\title{
Proved Viraemia in Asian Influenza (Hong Kong Variant) During Incubation Period
}

\author{
M. KHAKPOUR,* M.D. ; A. SAIDI, $\dagger$ B.N. ; K. NAFICY, $\ddagger$ M.D.
}

\begin{abstract}
Summary : During an outbreak of influenza specimens $\checkmark$ were obtained from 21 patients with influenza-like illnesses and from 29 healthy subjects in close contact with the patients. Throat washings from 12 of the patients were positive for influenza virus but virus was not detected from the blood specimens. One healthy contact became ill 12 hours after the specimens were obtained, and the virus was isolated from his blood and throat washings. The remaining contacts showed no clinical illness; but the virus was isolated from the throat washings of four of them, with no viral isolation from the blood specimens.
\end{abstract}

\section{Introduction}

The occurrence of viraemia in influenza infection has been suspected after recovery of the virus from extrapulmonary tissues of man and animals (Hamre et al., 1956 ; Kaji et al., 1959 ; Oseasohn et al., 1959). One of us (K.N.) reported isolation of Asian influenza virus from blood and throatwashing specimens of a physician suffering from an influenzalike illness (Naficy, 1963). Our further attempts to detect influenza virus from 18 proved cases of influenza were unsuccessful (K. Naficy, unpublished data). Stanley and Jackson (1966) showed that viraemia in influenza occurred in their human volunteers only during the first three days of the incubation period. We here report the successful isolation of Asian influenza virus, Hong Kong variant, from blood and throatwashing specimens of a patient who was in the incubation period, and an unsuccessful attempt to find viraemia in the same person and 21 other patients while demonstrating the clinical manifestations of influenza illness.

\section{Materials and Methods}

Subjects.-In mid-December 1968 we were informed of an outbreak of influenza illness among prisoners of the Tehran Ghasr Prison. The outbreak had apparently been present for a few weeks, during which period more than 200 prisoners had contracted the disease. Specimens were obtained from 21 patients in the first 24 hours of their illness, as well as from 29 healthy individuals who denied having had influenza-like symptoms in the two weeks prior to our visit. Both groups of prisoners gave informed consent to these procedures.

Specimens.-Throat washings and clotted and heparinized blood were obtained from all subjects. Sera from clotted blood were stored at $-20^{\circ} \mathrm{C}$. before use for serological tests ; throat washings and heparinized blood specimens were either inoculated within a few hours of collection or stored at $-70^{\circ} \mathrm{C}$. before inoculation. Second blood specimens were obtained three weeks later from only nine subjects.

Viral Isolations.-Each specimen was inoculated in a volume of $0.1 \mathrm{ml}$. into the amniotic sac of three 10-day-old embryonated hen's eggs, and incubated at $35^{\circ} \mathrm{C}$. for 40 hours, then left at $4^{\circ} \mathrm{C}$. overnight before harvesting the amniotic fluid. The

\footnotetext{
* Research Associate.

+ Senior Technician.

$¥$ Associate Professor.

Section of Viral Diseases, School of Public Health and Institute of Public

Health Research, Tehran University, P.O. Box 1310, Tehran, Iran.
}

fluid was tested for haemagglutinating activity; if positive, passage was carried out allantoically, otherwise at least one blind passage was performed amniotically.

Haemagglutination and Haemagglutination Inhibition Tests. - These tests were carried out according to the standard technique modified for microtitration by four haemagglutination units of antigen and chick red cells.

Reference Influenza Virus, Hong Kong Variant.-Importation of Hong Kong variant influenza virus to Iran apparently occurred during the Eighth International Congresses on Tropical Medicine and Malaria, Tehran, 7-15 September 1968. During the congresses one-third of the participants contracted the disease, and several strains were isolated from them in our laboratories (Saenz et al., 1969); these were confirmed by Dr. Pereira of the W.H.O. World Health Influenza Centre to be Hong Kong variant A2. One strain of these isolatesdesignated $30 \mathrm{~T}$-was used as a reference antigen.

Clinical Investigation.-Owing to the absence of any medical record in the Ghasr Prison, one of us (M.K.) made a daily visit to our subjects for six days and conducted clinical follow-ups.

\section{Results}

Clinical Manifestation.-Clinical manifestation of the disease consisted of fever, headaches, and generalized symptoms such as malaise, chills, anorexia, muscular pain, cough, sore throat, and chest pain in most of our patients, lasting from one to four days. No bacterial complication, encephalitis, or myocarditis was noted. All healthy subjects remained asymptomatic during the entire period of observation except one who developed fever and generalized symptoms 12 hours after the specimens were obtained.

Viral Isolation.-Twelve out of 21 throat-washing specimens obtained from the patients were positive for influenza virus either in the original inoculation or after the first passage. No virus was detected from the blood specimens of these patients in spite of two blind passages. Haemagglutination inhibition antibody determination in paired sera of seven patients revealed eightfold or greater rise both to the isolates and the reference antigen, except in one case. Table I summarizes these results in cases with positive viral isolations. No virus was isolated from the blood specimens of 28 healthy individuals who were in close contact with the patients and remained asymptomatic

TABLE I.-Antibody Titres to Asian Influenza (Hong Kong variant) in

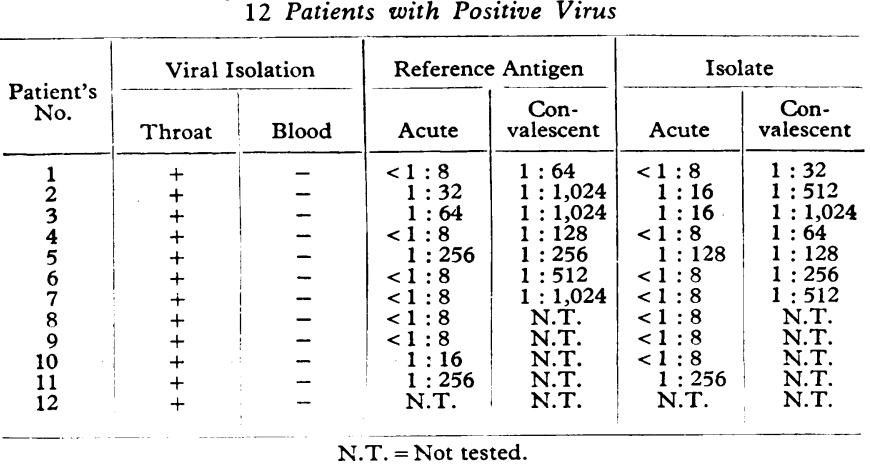


during our six-day observation, but throat washings from four subjects were positive. One healthy subject developed clinical illness 12 hours after blood and throat-washing specimens were obtained. These were positive for influenza, and the blood isolates were sent to the World Influenza Centre, being confirmed by Dr. Pereira to be the Hong Kong variant. Reisolation of the virus from the original blood specimen was successful, but no virus was detected from the blood specimens obtained 12 and 24 hours after clinical manifestation. The paired sera of this case showed a 16-fold rise both to the blood isolate and to the reference antigen. Table II lists viral isolation and haemagglutination inhibition antibody of healthy contacts, with positive isolations.

TABLE II.-Antibody Titres to Asian Influenza (Hong Kong variant) in

\begin{tabular}{|c|c|c|c|c|c|c|}
\hline \multirow{2}{*}{$\begin{array}{c}\text { Contact's } \\
\text { No. }\end{array}$} & \multicolumn{2}{|c|}{ Viral Isolation } & \multicolumn{2}{|c|}{ Reference Antigen } & \multicolumn{2}{|c|}{ Isolate } \\
\hline & Throat & Blood & Acute & $\begin{array}{c}\text { Con- } \\
\text { valescent }\end{array}$ & Acute & $\begin{array}{c}\text { Con- } \\
\text { valescent }\end{array}$ \\
\hline $\begin{array}{l}1 * \\
2 \\
3 \\
4 \\
5\end{array}$ & $\begin{array}{l}+ \\
+ \\
+ \\
+ \\
+\end{array}$ & $\begin{array}{l} \pm \\
\overline{-} \\
-\end{array}$ & $\begin{array}{c}1: 8 \\
1: 16 \\
1: 1,024 \\
1: 1,024 \\
1: 32\end{array}$ & $\begin{array}{c}1: 256 \\
\text { N.T. } \\
1: 128 \\
\text { N.T. } \\
\text { N.T. }\end{array}$ & $\begin{array}{rll}<<1 & : 8 \\
<1 & : 8 \\
1 & : 512 \\
1 & : 512 \\
1 & : 16\end{array}$ & $\begin{array}{c}1: 128 \\
\text { N.T. } \\
1: 64 \\
\text { N.T. } \\
\text { N.T. }\end{array}$ \\
\hline
\end{tabular}

- Developed clinical symptoms of influenza 12 hours after obtaining specimen.

\section{Discussion}

Recovery of influenza virus from extrapulmonary tissue of man and animals was the first indication of the occurrence of viraemia during influenza infection (Hamre et al., 1956 ; Kaji et al., 1959 ; Oseasohn et al., 1959).

Recovery of influenza virus from a patient's blood with clinical manifestations of the disease was the first report of proved viraemia in man (Naficy, 1963). Several other investigators, however, had failed to demonstrate viraemia during the clinical course of influenza infection (Kilbourne, 1959; Minuse et al., 1962 ; K. Naficy, unpublished data). Stanley and Jackson (1966), using human volunteers, showed clearly that viraemia occurs during the incubation period and that the virus was not detected after the third day of infection. Our results demonstrate that in 12 out of 21 patients with clinical signs of influenza virus was isolated from the throatwashing specimens but none from their blood; while in one patient-who proved to be in the incubation period at the time specimens were obtained-virus was obtained from both the blood and the throat washings. These results are in agreement with Stanley and Jackson's report and clearly explain accounts of unsuccessful attempts to demonstrate viraemia during the symptomatic phase of influenza infection.

The first successful report of the isolation of influenza virus from human blood, however, remains unexplained, since the isolation was made while the patient was symptomatic. Nevertheless, a review of the history of this patient showed that there had been two phases of clinical symptoms: (1) before admission and during the first two days of hospitalization, after which he became almost asymptomatic; and (2) a second phase from the fifth day, when he again experienced fever and chills (Naficy, 1963). Thus it is conceivable that fever and chills on the fifth day of hospitalization marked the onset of his influenza, unrelated to his undetermined previous infection, and the specimens were obtained during the incubation period.

It should be noted that four healthy subjects from whom virus was isolated remained asymptomatic. Two of these had a high haemagglutination inhibition antibody titre $(1: 1,024)$ in their acute sera. Thus it seems that, in spite of high circulating antibody, local replication of the virus in the nasopharyngeal cavity takes place, and may play a part in spreading the infection.

We wish to thank Dr. Pereira of the W.H.O. World Influenza Centre for his help in confirming the Hong Kong variant of our isolates, and Dr. Jamshidy of the Ghasr Prison health centre for his co-operation.

This study was partially supported by the funds of the public health research project of the Iranian Ministry of Health and the Plan Organization.

\section{REFERENCES}

Hamre, D., Appel, J., and Loosli, C. G. (1956). Journal of Laboratory and Clinical Medicine, 47, 182.

Kaji, M., Oseasohn, R., Jordan, W. S., jun., and Dingle, J. H. (1959). Proceedings of the Society for Experimental Biology and Medicine, $100,272$.

Kilbourne, E. D. (1959). Fournal of Clinical Investigation, 38, 266.

Minuse, E., Willis, P. W., III, Davenport, F. M., and Francis, T., jun. (1962). Fournal of Laboratory and Clinical Medicine, 59, 1016 Naficy, K. (1963). New England Fournal of Medicine, 269, 964

Oseasohn, R., Adelson, L., and Kaji, M. (1959). New England fournal of Medicine, 260, 509.

Saenz, A. C., Assaad, F. A., and Cockburn, W. C. (1969). Lancet, 1, 91. Stanley, E. D., and Jackson, G. G. (1966). Transactions of the Association of American Physicians, 79, 376

\section{Medical Memoranda}

\section{Thrombotic Microangiopathy Associated with Squamous Carcinoma}

British Medical fournal, 1969, 4, 209-210

The association of malignant disease with thrombophlebitis migrans is well recognized, and in some instances the lesions of the veins may be the first indication of occult malignant disease (Sproul, 1938). Such patients may also have nonbacterial thrombotic endocarditis (MacDonald and Robbins, 1957). On the other hand, disseminated arteriolar and capillary lesions occur much less frequently and do not normally give rise to clinical manifestations (McKay and Wahle, 1955; Azzopardi, 1966). Recently we had the opportunity of studying a patient who presented with features of thrombotic thrombocytopenic purpura, and only at necropsy did it become clear that these were associated with widespread thrombosis of small vessels and recurrent carcinoma.

\section{Case Report}

The patient was 56 years old when she was first seen in December 1963 complaining of rectal bleeding. This proved to be due to a rather poorly differentiated squamous carcinoma situated in the anal canal. Metastatic squamous carcinoma was also found in inguinal lymph nodes removed in a block dissection seven months later After this, however, she remained well for nearly five years until bleeding occurred from the colostomy in November 1968. When admitted to hospital, after having symptoms for three days, she was severely anaemic and had a thrombocytopenia $(\mathrm{Hb} 3.7 \mathrm{~g} . / 100 \mathrm{ml}$., white cells 9,000/cu. mm., and platelets $65,000 / \mathrm{cu}$. mm.). Blood transfusion brought some improvement in the haemoglobin level. Six days after admission, however, the platelet count was still only 